\title{
Editorial:
}

\section{The Journal of Clinical and Scientific Research: the road ahead!}

Two years ago, the Journal of Clinical and Scientific Research (JCSR) was born on the occasion of the Sri Venkateswara Institute of Medical Sciences (SVIMS) celebrating its $19^{\text {th }}$ Anniversary. ${ }^{1}$ The JCSR, is published quarterly, not only in the print format, but also in the "free full-text" format online (http://svimstpt.ap.nic.in/jcsr/jhome.htm). The journal has attracted more than 150 submissions in its first two years of existence from across the country and abroad and is growing fast! The journal is already indexed in Index Copernicus, Academic Index, Open J-gate, Directory of Open Access Journals (DOAJ), Journal Seek, Indian Science Abstracts, Geneva Foundation for Medical Education and Research, New Jour, Academic Journals Database, Research Bible and Directory of Research Journals Indexing (DRJ).

The JCSR is a peer-reviewed journal that promotes electronic submission and is able to sustain the fast-track processing with an average submission to decision time of 3 months. The JCSR does not charge any fees for submission, processing or publication from any of the authors. Consequent to the Medical Council of India's Amendment of the Postgraduate Medical Education Regulations, an increasing number of postgraduates and young faculty members from India are submitting manuscripts for publication. The free model devoid of any processing fee, fast-track processing time and free-full text online presence have facilitated JCSR to emerge as a fast growing journal which is indeed a boon, especially to young researchers who wish to publish their research work. ${ }^{2}$

During 2014, the JCSR is planning to provide Digital Object Identifier (DOI) numbers, the unique identification of the article and Quick response Code guiding to online access of the articles . We expect that these measures will facilitate rapid online location of articles published in the JCSR and once again sincerely hope that the best research gets published in the JCSR!

B. Vengamma Hon. Editor-in-Chief

P.V.L.N. Srinivasa Rao Exec. Editor-in Chief

Vengamma B, Srinivasa Rao PVLN. The Journal of Clinical and Scientific Research: the road ahead! J Clin Sci Res 2014;3:1.

\section{REFERENCES}

1. Vengamma B, Srinivasa Rao PVLN. The birth of a journal. J Clin Sci Res 2012;1:1.

2. Vengamma B. Journal of Clinical and Scientific Research: The year that has gone by! J Clin Sci Res 2012;2:1.

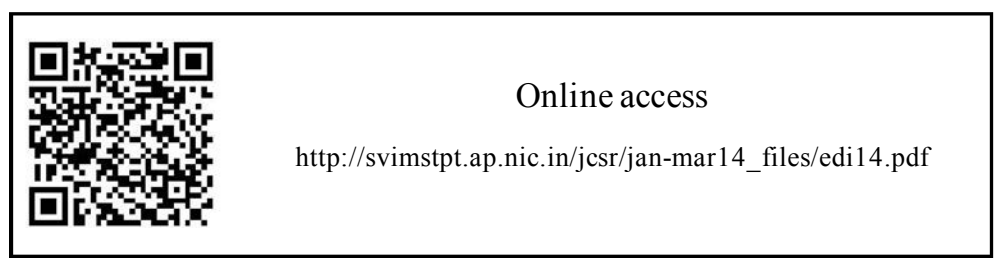

